\title{
«Nicht ärgern, nur wundern»
}

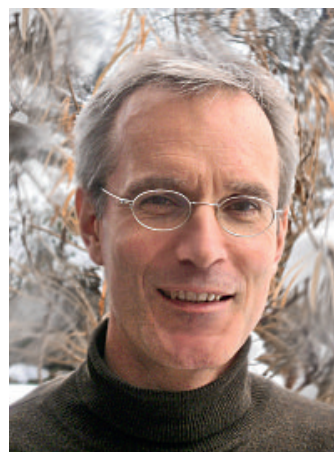

Bruno Kesseli
Diesen bis an die Grenze des sprachlich Zulässigen verdichteten Rat liess mir im Verlauf des zu Ende gehenden Jahres unser FMH-Präsident Jacques de Haller auf elektronischem Weg zukommen. Im Rahmen einer redaktionsinternen Mail-Diskussion hatte ich zuvor eine Passage in einem Beitrag als «ärgerlich» eingestuft. Den Auslöser meines Unmuts habe ich mittlerweile vergessen, was mir ein starkes Indiz dafür zu sein scheint, dass der kollegiale Rat weise war. Jedenfalls ist mir das präsidiale Bonmot seither des öfteren durch den Kopf geschossen - an Anlässen dafür mangelt es ja im Alltag nicht.

Ins Positive gewendet lässt sich bilanzieren, dass die Arbeit als Chefredaktor der SÄZ immer wieder Gelegenheit bietet, die Tugend des Gleichmuts zu entwickeln.

\section{Mit Befriedigung nehmen wir indes zur Kenntnis, dass die SÄZ intensiv gelesen und für die Berufstätigkeit als wichtig eingestuft wird.}

In der Tat scheinen sich die Vorstellungen darüber, wie die SÄZ sich inhaltlich und formal auszurichten und welche Interessen sie zu vertreten habe, in diesen (gesundheits-)politisch bewegten Zeiten zu polarisieren. Einige wünschen sich die SÄZ offenbar als Speerspitze gegen neoliberale Trends im Gesundheitswesen, andere empören sich aufgrund einer Blocher-Karikatur über die deplazierte politische Instrumentalisierung der SÄZ für linke Zwecke. Wieder andere haben Mühe damit, die in den Autorenrichtlinien festgelegten Regeln und die Kompetenzen der Redaktion zu akzeptieren. Eine Kollegin wünscht sich mehr kulturelle Beiträge, da genau dies im Berufsalltag zu kurz komme, ein Kollege verlangt mehr Bezug zur Tagesaktualität ... und so weiter.

Dazu kann nur wiederholt werden, was bereits bei früherer Gelegenheit betont wurde: Die SÄZ kann sich keine Partikularinteressen auf die Fahne schreiben, sie hat den Auftrag, die gesundheitspolitische Landschaft, insbesondere die Positionen der Ärzteschaft, in ihrer ganzen Breite abzubilden.

Bevor nun der Eindruck eines Gejammers entsteht, sei unmissverständlich betont: Nach fünf Jahren bereitet mir meine Tätigkeit für die SÄZ mehr Freude denn je. Das liegt sicher am guten Arbeitsklima bei EMH und am engagierten Redaktionsteam, dem für seinen Einsatz an dieser Stelle herzlich ge- dankt sei. Zu einem wesentlichen Teil liegt es aber auch an Ihnen, liebe Kolleginnen und Kollegen. Denn wie ich fast täglich erleben darf, besteht unsere Leserschaft zwar aus kritischen Zeitgenossen, die mitunter kein Blatt vor den Mund nehmen - sie sind in aller Regel im persönlichen Kontakt aber sehr konstruktiv und schätzen unsere Bemühungen um einen guten Service. Dies zu erleben, beflügelt immer wieder.

Eine vorweihnächtliche Bestätigung unserer subjektiven Eindrücke über den Stellenwert der SÄZ für die Leserinnen und Leser erhielten wir kürzlich von unverdächtiger Seite. Eine breit angelegte Leserumfrage des Instituts für Markt- und Sozialforschung gfszürich, die das begehrte WEMF-Siegel* erhalten hat, bestätigte, dass die Schweizerische Ärztezeitung in Bezug auf die gesamtschweizerische Reichweite konkurrenzlos dasteht - auch die übrigen Zeitschriften des Schweizerischen Ärzteverlags EMH wie Schweizerisches Medizin-Forum SMF, PrimaryCare oder Swiss Medical Weekly SMW schnitten hervorragend $a b^{\star *}$.

Richtig: Die Studie wurde von den Verlagen Groupe Médecine et Hygiène und dem Schweizerischen Ärzteverlag EMH in Auftrag gegeben (und von FMH, Interpharma und vips unterstützt). Doch renommierte Institute wie gfs-zürich - von der WEMF gar nicht zu sprechen - werden sich hüten, Gefälligkeitsresultate zu erzeugen: Die Auswirkungen auf ihren Ruf wären verheerend. Mit 2800 Ärztinnen und Ärzten, die an der Erhebung teilgenommen haben, setzt die Studie auch bezüglich des verwertbaren Datenmaterials einen bisher unerreichten Massstab.

Natürlich kann die unangefochtene Spitzenposition der SÄZ bezüglich der Reichweite nicht überraschen. Es ist uns durchaus bewusst, dass wir als offizielles Organ der FMH gewissermassen eine Monopolstellung haben. Mit Befriedigung nehmen wir indes zur Kenntnis, dass die SÄZ intensiv gelesen und für die Berufstätigkeit als wichtig eingestuft wird auch in den qualitativen Dimensionen werden durchwegs Spitzenwerte erreicht, wobei die Deutschschweizer Leserschaft uns etwas bessere Noten gibt als die Kolleginnen und Kollegen in der Romandie (dort dürfen wir der Revue Médicale Suisse zum hervorragenden Abschneiden gratulieren).

Auf den Lorbeeren ausruhen werden wir uns nicht, aber den Rückenwind aus der Leserumfrage nehmen wir gerne ins neue Jahr mit. Im Namen der Redaktion wünsche ich Ihnen frohe Festtage und für 2011 alles Gute. 